\title{
ПОНЯТИЕ ПОТЕРПЕВШЕГО В МЕЖДУНАРОДНОМ УГОЛОВНОМ ПРОЦЕССЕ
}

\begin{abstract}
Аннотация. В статье исследуются как акты регулирующие судопроизводство различные международные уголовные трибуналов, так и доктрина, посвящённые теме жертв в международном уголовном проиессе. Документы, регулирующие международный уголовный прочесс, не содержат специального определения лииа, пострадавшего от преступления. Применить иеликом понятие, принятое в национальном уголовном процессе, невозможно, т. к. в международных трибуналах пострадавшими являются зачастую значительные группы людей. Для целей уголовного прочесса невозможно признать потерпевшим и юридическое лицо. Автор также считает, что говорить о признании коллективов в качестве жертвы вряд ли возможно. Практика трибуналов аd hос показывает, что в ходе расследования они считают необходимым учет специальных потребностей отдельных типов пострадавщих. Это объясняется тем, что в Статуте и в Регламенте можно найти различные положения, обязываюшие Суд принимать во внимание интересы и личные обстоятельства пострадавших. Как следствие, автор проводит классификацию жертв (дети, лица, пострадавшие от сексуальных преступлений и т.п.).
\end{abstract}

Ключевые слова: Международное право, международный уголовный проиесс, международный уголовный трибунал, коллективная жертва, юридическое личо, международный уголовный суд, жертва, классификачия, наииональные судопроизводства, пострадавший от преступления.

Abstract: The article concerns the acts regulating the judicial procedures in various international criminal tribunals, as well as the doctrine regarding the issues of victims in the international criminal process. The documents regulating the international criminal process have no special definition of a person, to whom a crime has caused damage. It is impossible to wholly apply the definition applicable in the national criminal law, since in the international criminal tribunal victims are often rather large groups of persons. For the purposes of the criminal process, it is also impossible to recognize a legal entity as a victim. The author also considers that it is hardly plausible to recognize groups (collectives) of persons as victims. The practices of the ad hoc tribunals shows that in the course of the investigation they take into account the special needs of certain types of victims. It is due to the fact that the Statute and the Regulations involve various provisions obliging the Court to take into account the interests and personal situations of the victims. As a result, the author provides a classification of victims (children, victims of sexual crimes, etc.).

Keywords: International law, international criminal process, international criminal tribunal, collective victim, legal entity, international criminal court, victim, classification, national judicial procedures, victim of a crime.

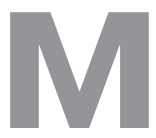

еждународное уголовное право - довольно новая отрасль международного права, и многие его понятия и категории пока не полностью сформировались. Понятие потерпевшего относится как раз к таким не вполне определившимся понятиям.

В нормативном массиве международного уголовного права невозможно найти юридическое определение жертвы или пострадавшего; такая ситуация характерна и для национальных систем уголовного права, считают многие авторы. П.Шифле, например, пишет: «Юридическая терминология содержит такие термины как «заявитель», «пострадавшая сторона» или «жалующийся свидетель». Приходится признать, что «жертва»- это термин криминологии, а в системе уголовного права жертва характеризуется в таких терминах, как заявитель или тому подобное'

Однако в том, что касается российского законодательства, Е.Н.Трикоз отмечает, что в ст.52 Конституции Российской Федерации упоминается процессуальная фигура потерпевшего с указанием на гарантии и охрану его прав в сфере правосудия, равный доступ к осуществлению правосудия и реализацию своего права на возмещение ущерба.

\footnotetext{
${ }^{1}$ Chifflet $P$. The Role and Status of the Victim//Boas G., Schabas W. (eds.) International Criminal Law Developments in the Case Law of the ICTY. 2003. P. 111.
} 
Кроме того, в ряде статей УПК РФ расшифровываются понятие потерпевшего от преступления и его процессуальный статус².

Впервые в международных документах термин «жертва» был применен в Резолюции Генеральной Ассамблеи о принципах правосудия для жертв 1985 г.

В п.1 сказано: «Под термином «жертвы» понимаются лица, которым индивидуально или коллективно был причинен вред, включая телесные повреждения или моральный ущерб, эмоциональные страдания, материальный ущерб или существенное ущемление их основных прав в результате действия или бездействия, нарушающего действующие национальные уголовные законы государств-членов, включая законы, запрещающие преступное злоупотребление властью». При этом уточняется, что то или иное лицо может считаться «жертвой» независимо от того, был ли установлен, арестован, передан суду или осужден правонарушитель, а также независимо от родственных отношений между правонарушителем и жертвой.

Кроме лица, которое можно назвать «непосредственной», или «прямой» жертвой, в Декларации содержится также определение лица, которое можно назвать «непрямой», или «косвенной» жертвой. Это близкие родственники или иждивенцы непосредственной жертвы, а также лица, которым был причинен ущерб при попытке оказать помощь жертвам, находящимся в бедственном положении, или предотвратить виктимизацию.

Подобное определение содержится и в Европейской конвенции о выплате компенсации жертвам тяжких преступлений, принятой в 1983 г. в рамках Совета Европы ${ }^{3}$.

В ст.2 сказано, что государства обязаны участвовать в компенсациях тем, кто потерпел серьезный физический ущерб или вред здоровью непосредственно вследствие намеренного акта насилия; а также иждивенцам тех, кто скончался в результате такого преступления. В Рекомендации Комитета министров Совета Европы «О положении потерпевшего в рамках уголовного процесса» ${ }^{4}$ прямого определения потер-

${ }^{2}$ Трикоз Е.Н. Особенности защиты жертв преступлений в национальном законодательстве и международном уголовном процессе//Международное уголовное правосудие, с.374.

${ }^{3}$ Европейская конвенция о выплате компенсации жертвам тяжких преступлений. Ратифицирована 25-ю государствами Совета Европы. Россия не участвует.// CoE Doc. ETS No. 116 .

${ }^{4}$ СОВЕТ ЕВРОПЫ.РЕКОМЕНДАЦИЯ № R (85) 11 КОМИТЕТА певшего (жертвы) не содержится, однако сказано, что следует уделять больше внимания лицам, которым нанесен физический, психологический, материальный и социальный ущерб.

Перейдем теперь к Международным уголовным трибуналам по Руанде и Югославии. Определение потерпевшего в их Регламентах более узкое, чем в Декларации Генеральной Ассамблеи 1985 г. В них сказано, что жертва - это лицо, в отношении которого совершено преступление, подпадающее под юрисдикцию трибунала (Правило 2А Регламента Трибунала для Югославии и Правило 2А Регламента Трибунала по Руанде). Необходимо учесть, что по образцу Регламента Трибунала по Руанде составлен Регламент Специального суда для Сьерра-Леоне, и указанное выше определение составляет Статью 14 его Регламента.

В Постановлении Переходной администрации Восточного Тимора № 2001/10 о создании Комиссии для установления фактов и примирения на Восточном Тиморе также сказано: «Жертва» означает лицо, которое в коллективном или индивидуальном порядке потерпело ущерб, в том числе физический или моральный, эмоциональные страдания, экономические потери или значительное вторжение в его или ее права в результате действий или бездействия, в отношении которых Комиссия обладает юрисдикцией на проведение расследование; «жертва» включает также родственников или иждивенцев лица, потерпевшего индивидуальный ущерб» 5 .

В литературе определения жертвы, предусмотренные документами трибуналов $a d h o c$, не раз подвергались критике как не отражающие Декларацию Генеральной Ассамблеи 1985 г., которая расценивается как международный стандарт; особенно многие эксперты и неправительственные международные организации, происходящие из стран «континентального права». Так, Д.Дона-Каттэн пишет: «Определения, заложенные в документах трибуналов $a d h o c$, то есть четко привязанное к «непосредственной» жертве, является недостаточным и вызывает сомнения в эффективности процесса разбирательства

МИНИСТРОВ СОВЕТА ЕВРОПЫГОСУДАРСТВАМ-ЧЛЕНАМ «О положении потерпевшего в рамках уголовного права и процесса». Принята Комитетом Министров 28 июня 1985 г. на 387-ом заседании Представителей Министров. CoE Doc. Recommendation No. R(85)1 1Cм. сайт неправительственной организации «Сопротивление»: «http://www.soprotivlenie.org/?id=96»: ${ }^{5}$ UN Doc. UNTAET/REG/2001/10, Section 1(n). 
в этих трибуналах, поскольку не учитывает особенности континентальных правовых систем» ${ }^{6}$

Нужно сказать, что судьи трибуналов по Югославии и Руанде неоднократно возвращались к этому вопросу на пленарных заседаниях; многие из них настаивали на внесении изменений с целью учета правовых идей всех стран; однако никаких изменений в определение жертвы так и не было внесено, и оно остается неизменным с 14 марта 1994 г.. когда Регламент, одобренный судьями на основании ст.15 Статута Трибунала по Югославии, вступил в силу. Тем не менее, во Втором ежегодном докладе Трибунала для Югославии указано, что Отдел секретариата по вопросам жертв и свидетелей применяет подходящие стандарты ООН при формулировании программ поддержки и защиты свидетелей и ссылается на Декларацию Генеральной Ассамблеи 1985г. в качестве такого стандарта7.

Возможность такого творческого подхода может объясняться тем, что в целом ни в Югославском, ни в Руандийском трибунале регулированию положения жертв не придавалось большого значения.

Что касается Международного уголовного суда, то в преддверии принятия его Статута состоялось довольно много дискуссий об определении потерпевшего (жертвы). В частности, следует обратить внимание на результаты работы Международного семинара о доступе жертв преступления к Международному уголовному суду, который был организован правительством Франции в Париже в апреле 1999 г. На этом семинаре секция № 1 предложила развернутое определение:

- «жертва» означает любое лицо или группу лиц, которым индивидуально или коллективно, прямо или косвенно, нанесен вред в результате преступления, подпадающего под юрисдикцию Суда;

- «вред» означает физический или психический ущерб, эмоциональные страдания, экономические потери или существенное нарушение основных прав;

- «жертва» в надлежащих случаях может означать также организацию или учреждение, которым нанесен непосредственный вред 8

\footnotetext{
${ }^{6}$ Donat-Cattin D. Article 68-Protection of Victims and Witnesses and their Participation in the Proceedings//O.Triffterer (ed.). Commentary on the Rome Statute of the International Criminal Court: Observer's Notes, Article by Article. 1999, p. 884.

${ }^{7}$ UN Doc. A/50/365, par. 116.

${ }^{8}$ International Seminar on Access of Victims to the International Criminal Court. Draft Rule X (Workshop 1), reprinted in UN Doc. PCNICC/1999/WGRPE/INF/2, Paris, 1999.
}

Таким образом, отличие парижского проекта от Декларации 1985 г. состоит в том, что в нем возможно отнести к жертвам также непосредственно пострадавшие организации, то есть юридические лица. Другое отличие - в парижском проекте не названы косвенные жертвы.

Однако многие делегации - члены Подготовительной комиссии по созданию Международного уголовного суда, которой было поручено составить проект Регламента МУС, считали определение, изложенное в Парижском проекте, слишком детализированным. В окончательном проекте текста Регламента, принятом в июне 2000 г., содержится менее детальное определение жертвы:

«Для целей Статута и Правил процедуры и сбора доказательств:

a) «жертва» означает физическое лицо, которому нанесен вред в результате совершения любого преступления в пределах юрисдикции Суда;

б) к жертвам могут быть отнесены организации или учреждения, которым нанесен непосредственный вред любому их имуществу, если оно предназначено для религиозных, образовательных, художественных или благотворительных целей, либо их историчеким сооружениям, медицинским учреждениям и другим местам и объектам гуманитарного назначения».

В Римский статут определение жертвы не вошло, хотя сами жертвы преступления упоминаются в Статуте неоднократно.

9 сентября 2002 г. Ассамблеей государств-участников Римского статута был принят Регламент Международного уголовного суда ${ }^{9}$, который содержит общее определение жертвы; оно явно основано на Декларации 1985 г. и предназначено для всех случаев появления жертвы в судебном процессе (в целях защиты, участия и предоставления компенсаций $)^{10}$.

В отличие от парижского проекта, в ст.85 Регламента не проводится различие между индивидуальными и коллективными жертвами; однако в Правиле 97 (1) об оценке компенсаций говорится о том, что суд может вынести решение о предоставлении компенсаций на коллективной основе, если найдет это подходящим. Из этого положения неко-

\footnotetext{
${ }^{9}$ Международный уголовный суд. Правила процедуры: ICC Doc. ICC-ASP/1/3, pp. 5 and 10

${ }^{10}$ Международный уголовный суд. Правила процедуры. Rule 85 of the ICC RPE.
} 
торые авторы делают вывод о том, что в качестве жертвы может быть признана организация, то есть, при совершении некоторых преступлений надлежит считать жертвами группы людей, а не отдельных индивидов. М. Шериф Бассиуни утверждает, например: «Коллективная жертва - это категория лиц, пострадавших именно потому, что они принадлежали к определенной группе населения» ${ }^{11}$.

С нашей точки зрения, это недостаточно обоснованный вывод. Правило 97 трактует не понятие жертвы, а понятие компенсации, поэтому вернее было бы говорить о различных формах компенсаций, не только материального, но и морального типа, например, в виде реабилитации неправомерно осужденных или репрессированных лиц. Говорить же о признании коллективов в качестве жертвы вряд ли возможно.

В Регламенте не проводится и различие между прямыми жертвами и косвенными, однако, поскольку в определении нет и ограничения прямыми жертвами, правомерно, видимо, включать в число жертв и косвенные.

Возможна дальнейшая некоторая классификация жертв преступлений: дети, лица, пострадавшие от сексуальных преступлений и т.п. Составители Статута и Регламента не стали проводить дальнейшей классификации. Правда, в статье 43 (6) Статута и Правиле 93 Регламента из всех жертв выделяются те, кто предстает перед судом, но их вряд ли можно считать отдельной категорией.

Как бы то ни было, в Статуте и в Регламенте можно найти различные положения, обязывающие Суд принимать во внимание интересы и личные обстоятельства пострадавших; это означает, что Суд должен учитывать такие факторы, как возраст, пол и состояние здоровья соответствующего лица ${ }^{12}$.

Практика трибуналов ad hoc показывает, что в ходе расследования они считают необходимым учет специальных потребностей отдельных типов пострадавших.

\section{Библиография:}

1. Bassiouni, M. Cherif. The Protection of 'Collective Victims' in International Law//M.C. Bassiouni (ed.), International Protection of Victims. 1988, p. 183..

2. Chifflet P. The Role and Status of the Victim//Boas G., Schabas W. (eds.) International Criminal Law Developments in the Case Law of the ICTY. 2003. P. 111.

3. Donat-Cattin D. Article 68-Protection of Victims and Witnesses and their Participation in the Proceedings//O.Triffterer (ed.). Commentary on the Rome Statute of the International Criminal Court: Observer's Notes, Article by Article. 1999 , p. 884.

4. Каламкарян Р.А. Роль Международного Суда ООН в деле поддержания международного правопорядка // NB: Международное право. - 2013. - № 1. - C.184-214. DOI: 10.7256/2306-9899.2013.1.690. URL: http://e-notabene.ru/wl/ article 690.html

5. Каламкарян Р.А. Включенность Российской Федерации в деятельность Международного Суда ООН в деле обеспечения международной законности и правопорядка // NB: Международное право. - 2013. - № 2. - C.85-118. DOI: 10.7256/2306-9899.2013.2.691. URL: http://e-notabene.ru/wl/article_691.html

6. .Г. Шинкарецкая. Изъятие из компетенции судебных учреждений дел, относящихся к внутренней компетенции государства // Право и политика. - 2010. - № 3.

7. Г.Г. Шинкарецкая. Запрет злоупотребления международной судебной процедурой как фактор обеспечения судебного процесса // Право и политика. - 2010. - № 2.

8. . А. Тарнавский, О. С. Акулин. Отдельные проблемные вопросы относительно процессуальной фигуры потерпевшего в уголовном судопроизводстве России // Право и политика. - 2011. - № 12. - С. 104-107.

9. Нафикова Г.А.. Правозащитный аспект механизма реализации принципа охраны прав и свобод человека и гражданина // Политика и Общество. - 2013. - № 7. - С. 104-107. DOI: 10.7256/1812-8696.2013.7.5001.

10. П.А. Кабанов. Криминологическая концепция криминальной политической виктимологии // Право и политика. 2012. - № 11. - С. 104-107.

11. В. А. Оганесян. Решения международных судов по правам человека как особый источник развития и соблюдения принципов уголовного правосудия // Международное право и международные организации / International Law and International Organizations. - 2012. - № 1. - C. 104-107

${ }^{11}$ Bassiouni, M. Cherif. The Protection of 'Collective Victims' in International Law//M.C. Bassiouni (ed.), International Protection of Victims. 1988, p. 183..

\footnotetext{
${ }^{12}$ См. ст.54(1) 68 (1) Статута и Правила 86 и 88 Регламента.
} 
DOI: $10.7256 / 2226-6305.2014 .3 .11555$

При цитировании этой статьи сноска на doі обязательна

Международное право и международные организации•з•2014 International Law and International Organizations

12. Н. И. Костенко Организация Объединенных Наций в развитии международной уголовной юстиции // Международное право и международные организации / International Law and International Organizations. - 2012. - 3. - C. 71 - 82.

\section{References (transliterated):}

1. Bassiouni, M. Cherif. The Protection of 'Collective Victims' in International Law//M.C. Bassiouni (ed.), International Protection of Victims. 1988, p. 183..

2. Chifflet P. The Role and Status of the Victim//Boas G., Schabas W. (eds.) International Criminal Law Developments in the Case Law of the ICTY. 2003. R. 111.

3. Donat-Cattin D. Article 68-Protection of Victims and Witnesses and their Participation in the Proceedings//O.Triffterer (ed.). Commentary on the Rome Statute of the International Criminal Court: Observer's Notes, Article by Article. 1999 , p. 884.

4. Kalamkaryan R.A. Rol' Mezhdunarodnogo Suda OON v dele podderzhaniya mezhdunarodnogo pravoporyadka // NB: Mezhdunarodnoe pravo. - 2013. - № 1. - S.184-214. DOI: 10.7256/2306-9899.2013.1.690. URL: http://e-notabene.ru/wl/ article_690.html

5. Kalamkaryan R.A. Vklyuchennost' Rossiiskoi Federatsii v deyatel'nost' Mezhdunarodnogo Suda OON v dele obespecheniya mezhdunarodnoi zakonnosti i pravoporyadka // NB: Mezhdunarodnoe pravo. - 2013. - № 2. - S.85-118. DOI: 10.7256/23069899.2013.2.691. URL: http://e-notabene.ru/wl/article_691.html

6. G.G. Shinkaretskaya. Iz"yatie iz kompetentsii sudebnykh uchrezhdenii del, otnosyashchikhsya k vnutrennei kompetentsii gosudarstva // Pravo i politika. - 2010. - № 3.

7. G.G. Shinkaretskaya. Zapret zloupotrebleniya mezhdunarodnoi sudebnoi protseduroi kak faktor obespecheniya sudebnogo protsessa // Pravo i politika. - 2010. - № 2.

8. O. A. Tarnavskii, O. S. Akulin. Otdel'nye problemnye voprosy otnositel'no protsessual'noi figury poterpevshego v ugolovnom sudoproizvodstve Rossii // Pravo i politika. - 2011. - № 12. - S. 104-107.

9. Nafikova G.A.. Pravozashchitnyi aspekt mekhanizma realizatsii printsipa okhrany prav i svobod cheloveka i grazhdanina // Politika i Obshchestvo. - 2013. - № 7. - S. 104-107. DOI: 10.7256/1812-8696.2013.7.5001.

10. P.A. Kabanov. Kriminologicheskaya kontseptsiya kriminal’noi politicheskoi viktimologii // Pravo i politika. - 2012. - № 11. - S. 104-107.

11. V. A. Oganesyan. Resheniya mezhdunarodnykh sudov po pravam cheloveka kak osobyi istochnik razvitiya i soblyudeniya printsipov ugolovnogo pravosudiya // Mezhdunarodnoe pravo i mezhdunarodnye organizatsii / International Law and International Organizations. - 2012. - № 1. - S. 104-107

12. N. I. Kostenko Organizatsiya Ob"'edinennykh Natsii v razvitii mezhdunarodnoi ugolovnoi yustitsii // Mezhdunarodnoe pravo i mezhdunarodnye organizatsii / International Law and International Organizations. - 2012. - 3. - C. 71 - 82. 